\title{
Original article \\ Influence of altiazem pp-180 on hemodynamic parameters in arterial hypertension patients under outpatient conditions
}

\author{
Zhakiyeva $\mathrm{GR}^{1}$, Tulegenova $\mathrm{LM}^{2}$, Ibragimova $\mathrm{NZ}^{3}$, Kelimberdiyev $\mathrm{SM}^{4}$, Tokbayeva $\mathrm{KK}^{5}$
}

\begin{abstract}
$\underline{\text { Abstract }}$
Background: The objective is to study the time-dependent hemodynamic effects of altiazem PP-180 and the blood circulation parameters in patients with arterial hypertension of the II degree in outpatient polyclinic conditions. Methods: The study included 78 patients with essential II grade $\mathrm{AH}$ aged 42 to 73 years (mean age of $57.65 \pm 0.6$ ). Among them were 28 men and 50 women. The duration of the disease ranged from 4 to 23 years (an average of 9.2 \pm 0.12 ). All the groups involved in the research were divided into two subgroups: the main group and the control group. The control group included 30 patients, who took A-180 once a day at non-fixed hours. The main group included 48 patients, who were divided into random subgroups depending on the time they took A-180 once a day. Within 3 days prior to treatment and during the 10-day treatment course, the medical staff measured all the pateints' heart rate and blood pressure by NC Korotkoff every 3 hours, 6 times a day. The patients' heart rate and blood pressure were alternatively self-measured. Prior to treatment and at the end of the 10-day course of therapy with altiazem PP-180, all the patients involved in the research underwent ECG examination and echocardiography on the Aloka machine (Japan). Results: The most favorable hemodynamic support for the hypotensive effect of altiazem PP-180 was observed when patients took it at 7 a.m., 10 a.m. and 10 p.m. in their normal mode of work and rest. When patients took altiazem PP-180 at 1 p.m, 4 p.m. and 7 p.m., its hypotensive effect was due to less favorable hemodynamic support. Conclusions: When taken at different hours of the day - both fixed and non-fixed hours - altiazem PP-180 caused a distinct hypotensive effect in patients with the II degree $\mathrm{AH}$ in outpatient polyclinic conditions.
\end{abstract}

Keywords: arterial hypertension; altiazem; hemodynamic parameters; outpatient conditions.

Bangladesh Journal of Medical Science Vol. 17 No. 03 July'18. Page : 360-368 DOI: http://dx.doi.org/10.3329/bjms.v17i3.36990

\section{$\underline{\text { Introduction }}$}

The problem of optimization of a long-term supportive therapy of uncomplicated arterial hypertension ( $\mathrm{AH})$ is one of the most urgent issues in modern cardiology. Despite successful treatment of this disease a lot of problems related to the condition of elevated arterial blood pressure (ABP) remain unsolved, and the results of dispensary observations tend to be unsatisfactory. Due to the lack of clear scientifically grounded recommendations on

1. Gulzhakhan Ryskalievna Zhakiyeva, Associate Professor, Head of the Department of General Practice of Internship and Postgraduate Training

2. Lyubov Muratovna Tulegenova, Professor, Department of General Practice of Internship and Postgraduate Training

3. Nuria Zakarievna Ibragimova, Associate Professor, Department of General Practice of Internship and Postgraduate Training

4. Saubet Molbaevich Kelimberdiyev, Associate Professor, Department of General Practice of Internship and Postgraduate Training

5. Kulsin Kolganatovna Tokbayeva, Associate Professor, Department of Internship Therapeutic Profile with Postgraduate Training, West Kazakhstan Marat Ospanov State Medical University, 1 Mareseva street, Aktobe 030019, Kazakhstan

Correspondence to: Gulzhakhan Ryskalievna Zhakiyeva, Associate Professor, Head of the Department of General Practice of Internship and Postgraduate Training, e-mail: gulzhahan.zhakieva@list.ru 
medication-assisted treatment of various types of $\mathrm{AH}$, doctors in practical healthcare are forced to administer treatment intuitively, based on their personal experience. Patients do not take medicine on regular basis, therefore their ABP can hardly be controlled and remains elevated $d^{1,2,3,4}$.

Therefore, the search for an optimal individualized approach to the treatment of $\mathrm{AH}$ patients with hypotensive drugs is considered to be an urgent issue. Selection of the time of day when the hypotensive action of a drug tends to be the most effective and leads to favorable hemodynamic changes in a patient seems quite promising. It would allow patients to decrease hypotensive drug dosage frequency and reduce drug load, which would result in a decrease of side effects of antihypertensive agents. Given a wide variety of hypotensive drugs practicing physicians are not always aware of the optimal time of drug intake and dosage during the day under outpatient conditions $\mathrm{s}^{5,6,7,8}$

At present, a great selection of hypotensive drugs is available with the drugs of calcium channel blocker class being of particular interest ${ }^{4,9,10,11}$. A number of research works demonstrate the ability of some drugs of this class to prevent the development of cardiovascular complications ${ }^{1,12,13,3}$. At the present time, extended-release diltiazem is widely used and highly researched from the perspective of evidence-based medicine ${ }^{13}$.

Diltiazem refers to non-dihydropyridine calcium channel blockers and produces an effect both on arteries and myocardium ${ }^{14,15,16,17}$.

Large-scale random research works targeted at the evaluation of clinical efficacy of such drugs have mainly covered clinical laboratory evaluation of diltiazem pharmacological effect. Diltiazem, presented in new 24-hour extended-release dosage forms, is regarded as the most effective. It takes an interposition between dihydropyridine drugs and verapamil derivatives. Unlike verapamil, it does not cause acute cardio depression and does not lead to a sudden excessive activation of the sympathetic nervous system resulting in tachycardia, as dihydropyridine drugs do. Besides, there are a lot of $\mathrm{AH}$ patients with co-morbidity who are not recommended to take drugs of a different class; in particular, these are tachycardia-prone patients, patients with pulmonary pathology, peripheral vasospasm-prone patients; in this instance, it would be preferable to use diltiazem ${ }^{18,15,8,17}$.

The study of both hypotensive and other effects of diltiazem would create an opportunity to comprehensively evaluate its efficacy in terms of arterial pressure control, its effect on endothelial dysfunction, and an opportunity to prevent cardiovascular complications.

At the present time, when administering hypotensive therapy, the preference is given to the drugs which are able not only to effectively control ABP but to influence primary pathological links while forming systematic $\mathrm{AH}$ due to their organ-protective action, as well. Ultimately, such an approach should improve the prognosis for $\mathrm{AH}$ patients, under the condition of drug chronic administration. In this regard, an integral part is taken by drugs, such as diltiazem, which are targeted at the correction of endothelium malfunction, i.e. correction of its dysfunction based on a 24-hour extended-release action ${ }^{19,20}$.

The results of large-scale research works testify to substantial advantages of the group of drugs represented by diltiazem ${ }^{12,20,16,17}$.

Various publications contain a large amount of information concerning the efficacy and safety of such drugs, including Altiazem-180 $7,2,21$.

Nevertheless, the problem of the study of timedependent effects of A-180, its Chrono efficacy under outpatient conditions based on a normal work/rest routine remains unsolved ${ }^{11,22}$.

The objective of the research - a study of timedependent hemodynamic effects of Altiazem PP180 and the parameters of blood circulation in II degree arterial hypertension patients under outpatient conditions.

\section{Materials and Methods}

The 78 II degree arterial hypertension patients aged 42 to 73 were enrolled in the research (average age $-57.65 \pm 0.6$ ). 28 research subjects were men and 50 were women. All the patients involved gave their consent for their parametres to be observed, analysed and published. Duration of the disease made up 4 to 23 years ( $9.2 \pm 0.12$ on average).

The average duration of the patients' dispensary observation amounted to 7.40 .11 years. All the research groups were divided into 2 parts: an experiment group and a control group. The control group consisted of 30 patients who were administered A-180 once a day at random hours, whereas the experimental group included 48 patients who were randomly assigned to take A-180 once a day at a set time.

The I group contained 8 patients who took $180 \mathrm{mg}$ of Altiazem once a day at waking hours (7.00 a.m.). The II group included 8 patients who took $180 \mathrm{mg}$ of Altiazem three hours after waking up (10.00 a.m.). 
The III group had 8 patients who took the prescribed drug 6 hours after waking up (at 01.00 p.m.). The group IV - 9 AH patients who took A-180 nine hours (9 hours) after waking up (04.00 p.m.). The V group contained 7 patients who took the drug 12 hours after waking up (at 07.00 p.m.), and the VI group included 8 patients who took A-180 fifteen hours after waking up (at 10.00 p.m.).

During 3 days prior to treatment and during 10 days of the treatment course by Altiazem PP-180 the patients had their ABP taken by means of Korotkoff sound technique and had their pulse measured 6 times a day every 3 hours by medical personnel or applying selfmeasurement.

All the patients in the research group underwent EKG and echocardiography procedures prior to and during the 10 day-course of treatment by Altiazem PP-180 by means of Aloka ultrasound equipment (Japan). The patients' systolic discharge (SD), enddiastolic dimension (EDD), end-systolic dimension (ESD), dimensions of aorta diameter and left atrium were measured. Cardiac minute output (CMO), stroke volume and cardiac indices (SVI and CI), total peripheral resistance, peripheral vascular resistance index (TPR and PVRI) and double product (DP) were determined according to generally accepted formulas. End-diastolic and end-systolic volumes (EDV and ESV) were determined according to Teicholz formula (1972).

Left ventricular mass (LVM) was determined in accordance with the formula suggested by American Heart Association and by American Society of Echocardiography. Interventricular septum thickness (IST) and left ventricular posterior wall thickness (LVPWT), end-diastolic dimension (EDD) measurement data were used. $\mathrm{LVM}=0,80 \times(1.04 \mathrm{x}$ (EDD + IST + LVPWT) - (EDD)).

During one week prior to drug administration, the patients did not take any other medicine that could influence their hemodynamics. The received data on chrono-drug-responsiveness to Altiazem $\mathrm{PP}$ in hypertensive disease (HD) patients, the measurements results of hemodyanamics indices prior and during treatment were analyzed by means of variation statistics method, including a differential method based on electronic data processing machine PC/AT.

The difference was considered accurate if the differential was $p<0.05$. In order to determine the circadian rhythm of hemodynamics parameters the method of Cosinor-analysis by Halberg (1965) and the linked samples method were applied.
The essence of cosinor-analysis is in cosine wave modeling of parameters, amplitude and acrophase deviation by means of the least square method ${ }^{23}$. Average daily rhythm level MESOR (MESOR Midline Estimating Statistic of Rhythm), equals the arithmetical mean amplitude value.

Rhythm acrophase, the time of the indices' highest value, shows how much the cosine wave peak, approximating the given biorhythm, lags behind the cosine wave peak of the reference rhythm. While studying daily rhythms the rhythm of the Earth's rotation around its axis is considered as reference rhythm with the assumed reference time of acrophase at midnight. The acrophase measurement units are time units (second, minute, hour) or tangent units (degrees).

The average amplitude of a daily rhythm presents the amount of difference between the index of maximum deviation and MESOR of approximating cosine wave. The amplitude measurement units may be expressed in the percentage of parameter deviation relative to MESOR or original physiological units.

Approximating curve or the researched rhythm " $U$ " can be formularized as follows:

$\mathrm{U}=\mathrm{Co}+\mathrm{C} \times \cos (\mathrm{W} \times \mathrm{T} \times \mathrm{J})$,

Where Co - average level around which deviation occurs; C - deviation amplitude; W - angular frequency (i.e. reciprocal of period duration); $\mathrm{t}$ time; $\mathrm{J}$ - acrophase.

Cosinor-analysis should be applied in two stages. At the first stage mathematical processing of data received during visual research has to be handled. It is called individual cosinor-analysis. During the first stage, basic parameters of every rhythm must be determined individually. Then average group cosinor-analysis must be done. The essence of this method is based on finding an average cosine wave for the group as a whole based on cosine waves peculiar to every individual separately.

Vector averaging of individual values must be performed and confidence intervals of amplitudes level and acrophase of daily deviation of the researched indices should be determined. It should be kept in mind that the parameters of individual group representatives may change.

Rhythm amplitude and acrophase are graphically represented in a circle in the form of a vector originating from the middle of the circle. Confidence limits of acrophase are depicted by lines tangent to an ellipse which shows the accuracy of the rhythm period. If the ellipse does not cover the center of the circle, the 24 hour rhythm period is $95 \%$ accurate, and 
if it covers the center of the circle, it is not accurate. Average amplitude deviation, acrophase which is the time period of maximum indices, and MESOR were determined within the bounds of the research.

While analyzing Chrono responsiveness to Altiazem PP the following criteria had to be considered:

1) set-in time for the stable clinical and hypotensive effect in days;

2) SABP, DABP, average ABP, DP within 24 hours prior to, during and after treatment;

3) SD, CI, CMO, SVI, TPR, PVRI, LVM dynamics prior to and after treatment;

4) mechanism of Altiazem PP-180 hypotensive effect;

5) changes in daily ABP, HR, DP profile prior to, during and at the end of the course of treatment;

6) characteristics of the 24-hour rhythm of all researched parameters, including MESOR, amplitude, and acrophase;

7) Determination of circadian rhythm of SABP, DABP, average BP, HR and DP prior to, during and at the end of the course of treatment by Altiazem PP-180.

The research was conducted with due consideration of international ethical guidelines, including European Convention on Human Rights and Biomedicine developed by the Council of Europe and any amendments thereto, as well as bioethical national legislative regulations.

\section{$\underline{\text { Research Results and Discussion }}$}

The conducted research testified to an evident hypotensive effect of A-180 at all drug intake times: both at a set time and at a random time.

Nevertheless, it must be noted that the most evident hypotensive effect was observed when the drug was administered at 07.00 a.m., 10.00 a.m. and 10.00 p.m. Thus, the following showings were observed: a significant decrease in a daily average SABP from 193.75 to $145.5 \mathrm{mmHg}$ (28\% decrease), DABP decreased from 105.625 to $81.25 \mathrm{mmHg}$ (23\% decrease) and average ABP - from 134.625 to $1203.125 \mathrm{mmHg}$ (25\% decrease).

The evident hypotensive effect was achieved due to a decrease of TPR from 2134.675 to 1602.375 (24\% decrease), PVRI from 1134.338 to 849.338 (25\% decrease). The decrease of HR from 90.0 to 71.75 beats per minute was observed (22\% decrease). Favorable hemodynamic effect of the drug was followed by a significant increase in cardiac output - SD increased from 60.625 to $71.6 \mathrm{ml}$. (18\%), ESV decreased from 59.3 to $39.2 \mathrm{ml}$. (33\%), EDV - from 128.5 to $100.7 \mathrm{ml}$. (21\%).
Ejection fraction increased from $45.3 \%$ to $52.6 \%$. The decrease of left ventricular mass from 400.4 to 296.8 g. (25\%) should be noted, as well. Hypotensive effect of the drug was achieved on the third day of treatment (Table 1).

The study of Chrono structure dynamics of circadian rhythms of some hemodynamics parameters affected by Altiazem when administered at 07.00 a.m. (at waking hours) testifies to the decrease of MESOR SABP, DABP, HR, Average ABP, and DP. A slight decrease of rhythm amplitude was observed, especially SABP, Average ABP и DP and a shift of SABP, DABP, HR, Average ABP и DP rhythms acrophase from late evening hours $(\approx 10.00$ p.m. $)$ to earlier evening hours $(\approx 07.00$ p.m.) and (Figure 1-3). The data presented in this work testify to a normalizing effect of A-PP-180 when administered at waking hours (at 07.00a.m.) on circadian hemodynamics organization.

When administered at 10.00 a.m. the drug showed a significant decrease of SABP: from 80.8 to 136.2 $\mathrm{mmHg}$ (24\%), DABP decreased - from 101.0 to $80.0 \mathrm{mmHg}(20 \%)$. A clear hypotensive effect was caused by the decrease of TPR: at 10.00 a.m. - from 2004.8 to 1563.0 dyn.sec.cm $(22 \%)$ as well as by the decrease of PVRI from 1192.8 to 869.1 dyn.sec. $\mathrm{cm} / \mathrm{m}(27 \%)$, which points to a vasodilatory effect of the drug.

A significant increase in cardiac output was also noted. Therefore SD increased from 58.2 to $74.1 \mathrm{ml}$. (27\%) and ejection fraction from $42 \%$ to $51.6 \%$. At the same time a decrease of ESV from 92.5 to $74.1 \mathrm{ml}$. (19\%) and EDV - from 153.8 to $120.5 \mathrm{ml}$. (21\%). Myocardium energy consumption decreased, which became evident due to the decrease of DP from 148.9 to 88.8 relative value units $(40 \%)$ ).

LVM decreased considerably (by $31 \%$ ) (Table 2). Clinical and hemodynamic effects were achieved on the $5^{\text {th }}$ day provided A-180 was administered at 10.00 a.m.

Similar results were achieved when A-180 was administered at 10.00 p.m.

Thus, the most evident hemodynamic effect of Altiazem PP-180 hypotensive action was observed when administered at 07.00 a.m., 10.00 a.m., 10.00 p.m..

On the contrary, taking Altiazem PP-180 at 01.00 p.m.; 04.00 p.m. and 07.00 p.m. as well as at random intake times of the day did not show an obvious hemodynamic effect of A-180.

The study of hemodynamic parameters when taking A-180 at 01.00 p.m. showed a decrease of cardiac 
output which led to a decrease of SD by $16 \%$ and ejection fraction $8.2 \%$. At the same time, a significant $40 \%$ increase of TPR and a $42 \%$ increase of PVRI was observed, which demonstrated a vasoconstrictive effect of Altiazem. Besides, a slight 11\% decrease of ESV and a 9\% decrease of EDV was noted. Clinical hypotensive effect of Altiazem became obvious on the 4th-5th day of treatment (Table 3).

Similar changes were observed when the drug was administered at 04.00 p.m.; 07.00 p.m. and at random times of the day.

Hypotensive effect of Altiazem within these time periods was conditioned by the decrease in cardiac output. An increase of TPR and PVRI should also be noted. In these series of research work, the dynamics of ESV and EDV was not favorable.

The analysis of the Chrono structure of circadian rhythms of hemodynamics parameters prior to and after Altiazem PP-180 has been administered at 01.00 p.m. testified to the damage of DABP rhythms Chrono structure (Figure 5). Along with the decrease of MESOR DABP disappearance of circadian rhythm DABP was noted at the end of treatment. The decrease of MESOR SABP was not significant - from $160.52 \pm 3.63$ to $150.64 \pm 2.41$ $\mathrm{mmHg}$, the rhythm amplitude remained unchanged and equaled $13.56 \pm 1.67 \mathrm{mmHg}$. The shift of rhythm SABP acrophase was insignificant (from 21.20 to 20.41). MESOR HR decreased from $84.88 \pm 1.74$ to $74.56 \pm 1.22$ beats per 1 minute. The HR amplitude changed insignificantly from $5.48 \pm 0.94$ to $3.90 \pm 0.69$ beats per minute. Similar to SABP acrophase HR rhythms acrophase also underwent an insignificant shift from 21.24 to 20.29. MESOR of average ABP and DP decreased, the amplitude of these rhythms also showed a noticeable reduction, the acrophase of these rhythms underwent a slight change similar to SABP and HR rhythms acrophase (Figure 4-5).

ESV decreased insignificantly, on the contrary, EDV increased by $5 \%$ when Altiazem was administered at 04.00 p.m. An insignificant decrease of LVM came under notice, as well. All hemodynamic effects were achieved for a little over than 5 days. Side effects were observed in one patient.

Considering the obtained results it has been concluded that it is reasonable to administer Altiazem PP-180 to patients at 07.00 a.m., 10.00 a.m., and 10.00 p.m. when the drug shows the most evident hypotensive effect.

Table 1. Effects of Altiazem PP-180 on hemodynamics parameters when administered at 07.00 a.m. (waking hours)

\begin{tabular}{|c|c|c|c|}
\hline \multirow[t]{2}{*}{ Parameters } & \multirow{2}{*}{$\begin{array}{l}\text { Prior to treatment } \\
M \pm \mathbf{m}\end{array}$} & \multicolumn{2}{|l|}{ After treatment } \\
\hline & & $\mathbf{M} \pm \mathbf{m}$ & P differ. \\
\hline $\mathrm{SABP}, \mathrm{mmHg}$ & $193.75 \pm 5.846$ & $147.5 \pm 2.339$ & $<0.0003$ \\
\hline DABP, $\mathrm{mmHg}$ & $105.625 \pm 2.214$ & $81.25 \pm 0.765$ & $<0.0002$ \\
\hline Average ABP, mmHg & $134.625 \pm 2.915$ & $103.125 \pm 1.152$ & $<0.0001$ \\
\hline HR, beats per 1 min. & $90.0 \pm 2.062$ & $71.75 \pm 1.598$ & $<0.0002$ \\
\hline $\mathrm{SD}, \mathrm{ml}$ & $60.625 \pm 2.304$ & $71.625 \pm 3.307$ & $<0.0029$ \\
\hline $\mathrm{CMO}, 1 / \mathrm{min}$ & $5.32 \pm 0.304$ & $5.239 \pm 0.209$ & $\approx 1.000$ \\
\hline $\mathrm{CU}, \mathrm{ml} / \mathrm{m}^{2}$ & $32.2 \pm 1.544$ & $38.125 \pm 2.319$ & $<0.0037$ \\
\hline $\mathrm{CI}, 1 / \mathrm{min} / \mathrm{m}^{2}$ & $2.775 \pm 0.171$ & $2.75 \pm 0.156$ & 1.000 \\
\hline TPR, dyn.s.cm ${ }^{-5}$ & $2134.675 \pm 166.896$ & $1602.375 \pm 86.307$ & $<0.01$ \\
\hline PVRI, dyn.s. $\mathrm{cm}^{-5} / \mathrm{m}^{2}$ & $1134.338 \pm 88.398$ & $849.338 \pm 38.124$ & $<0.01$ \\
\hline LVM, gr. & $400.4 \pm 39.202$ & $296.85 \pm 19.77$ & $<0.018$ \\
\hline $\mathrm{ESV}, \mathrm{ml}$ & $59.375 \pm 00$ & $39.25 \pm 0.06$ & $<0.005$ \\
\hline $\mathrm{EDV}, \mathrm{ml}$ & $128.5 \pm 00$ & $100.75 \pm 8.93$ & $\approx 0.05$ \\
\hline $\mathrm{EF}, \%$ & 45.375 & 52.625 & \\
\hline DP, relative value units & $174.5 \pm 7.671$ & $108.5 \pm 4.88$ & $<0.004$ \\
\hline \multicolumn{4}{|l|}{ Side effects } \\
\hline $\begin{array}{l}\text { The day when the effect } \\
\text { of drug administration } \\
\text { can be observed. }\end{array}$ & $3.25 \pm 0.153$ & & \\
\hline
\end{tabular}


Table 2. Effect of Altiazem PP-180 on hemodynamics parameters at 10.00 a.m. intake time (3 hours after waking up)

\begin{tabular}{|c|c|c|c|}
\hline \multirow[t]{2}{*}{ Parameters } & \multirow{2}{*}{$\begin{array}{l}\text { Prior to treatment } \\
\mathbf{M} \pm \mathbf{m}\end{array}$} & \multicolumn{2}{|l|}{ After treatmentcp } \\
\hline & & $\mathbf{M} \pm \mathbf{m}$ & $P$ differ. \\
\hline $\mathrm{SABP}, \mathrm{mmHg}$ & $180.875 \pm 5.029$ & $136.250 \pm 3.03$ & $<0.0004$ \\
\hline DABP, $\mathrm{mmHg}$ & $101.0 \pm 0.935$ & $80 \pm 0$ & $<0.0001$ \\
\hline Average ABP, mmHg & $123.75 \pm 2.344$ & $98.750 \pm 1.042$ & $<0.0002$ \\
\hline HR, beats per $1 \mathrm{~min}$. & $85.75 \pm 1.433$ & $68.375 \pm 1.620$ & $<0.0007$ \\
\hline $\mathrm{SD}, \mathrm{ml}$. & $58.25 \pm 3.454$ & $74.125 \pm 1.980$ & $<0.0039$ \\
\hline $\mathrm{CMO}, 1 / \mathrm{min}$ & $5.293 \pm 0.343$ & $4.864 \pm 0.349$ & $\approx 1.000$ \\
\hline SVI, $\mathrm{ml} . / \mathrm{m}^{2}$ & $35.65 \pm 2.348$ & $39.238 \pm 2.652$ & $\approx 1.000$ \\
\hline $\mathrm{CI}, \mathrm{l} / \mathrm{min} / \mathrm{m}^{2}$ & $2.738 \pm 0.259$ & $2.913 \pm 0.165$ & $\approx 1.000$ \\
\hline TPR, dyn.s.cm ${ }^{-5}$ & $2004.875 \pm 178.95$ & $1563.413 \pm 70.762$ & $<0.02$ \\
\hline PVRI, dyn.s.cm ${ }^{-5} / \mathrm{m}^{2}$ & $1192.863 \pm 107.523$ & $869.138 \pm 38.360$ & $<0.013$ \\
\hline LVM, gr. & $377.463 \pm 40.367$ & $260.175 \pm 23.42$ & $<0.013$ \\
\hline $\mathrm{ESV}, \mathrm{ml}$ & $92.51 \pm 0.01$ & $74.125 \pm 0.01$ & $<0.05$ \\
\hline $\mathrm{EDV}, \mathrm{ml}$ & $153.875 \pm 00$ & $120.5 \pm 3.68$ & $\approx 0.05$ \\
\hline $\mathrm{EF}, \%$ & 42.0 & 51.625 & $\approx 0.05$ \\
\hline DP, relative value units & $148.95 \pm 5.653$ & $88.8 \pm 2.896$ & $<0.0002$ \\
\hline Side effects & \multicolumn{3}{|l|}{1} \\
\hline $\begin{array}{l}\text { The day when the effect of } \\
\text { drug administration can be } \\
\text { observed. }\end{array}$ & \multicolumn{3}{|l|}{$5.25 \pm 0.293$} \\
\hline
\end{tabular}

Table 3. Effect of Altiazem PP-180 on hemodynamics parameters at 01.00 p.m. intake time (6 hours after waking up)

\begin{tabular}{|l|l|l|l|}
\hline \multirow{2}{*}{ Parameters } & Prior to treatment & After treatment & P differ. \\
\cline { 2 - 4 } & $\mathbf{M} \pm \mathbf{m}$ & $\mathbf{M} \pm \mathbf{~ m}$ & $<0.0001$ \\
\hline SABP, $\mathrm{mmHg}$ & $190.0 \pm 3.536$ & $142.5 \pm 2.339$ & $<0.0001$ \\
\hline DABP, $\mathrm{mmHg}$ & $100.625 \pm 0.585$ & $80.625 \pm 0.585$ & $<0.0001$ \\
\hline Average ABP, mmHg & $130.125 \pm 1.096$ & $101.0 \pm 0.984$ & $<0.0002$ \\
\hline HR beats per 1 minute. & $92.00 \pm 1.658$ & $72.5 \pm 1.723$ & $<0.0012$ \\
\hline SD, $\mathrm{ml}$. & $71.75 \pm 1.998$ & $60.25 \pm 2.409$ & $<0.004$ \\
\hline CMO, $1 . / \mathrm{min}^{2}$ & $6.284 \pm 0.329$ & $3.876 \pm 0.352$ & $<0,001$ \\
\hline SVI, $\mathrm{ml} . \mathrm{m}^{2}$ & $37.925 \pm 1,140$ & $31,713 \pm 1,353$ & $<0.005$ \\
\hline CI, $1 . / \mathrm{min}^{2} \mathrm{~m}^{2}$ & $3,293 \pm 0.191$ & $2.084 \pm 0.211$ & $<0.10$ \\
\hline TPR, dyn.s.cm ${ }^{-5}$ & $1728.188 \pm 97.847$ & $2429.013 \pm 314, .757$ & $<0.08$ \\
\hline PVRI, dyn.s. cm. ${ }^{-5} / \mathrm{m}^{2}$ & $901.350 \pm 48.128$ & $1287.363 \pm 156.75$ & $<0.01$ \\
\hline LVM, gr. & $303.225 \pm 21.763$ & $248.050 \pm 20.122$ & $<0.1$ \\
\hline ESV, $\mathrm{ml}$. & $118.375 \pm 00$ & $91.5 \pm 00$ & $\approx 0.05$ \\
\hline EDV, $\mathrm{ml}$. & $181.0 \pm 0.312$ & $149.0 \pm 0 ., 75$ & $<$ \\
\hline EF, \% & 51.875 & 43.625 & $<0.0001$ \\
\hline DP, relative value units & $175.00 \pm 5.839$ & $106.80 \pm 2.901$ & \\
\hline Side effects & 1 & & \\
\hline $\begin{array}{l}\text { The day when the effect of } \\
\text { drug administration can be } \\
\text { observed. }\end{array}$ & 4.875 & & \\
\hline
\end{tabular}




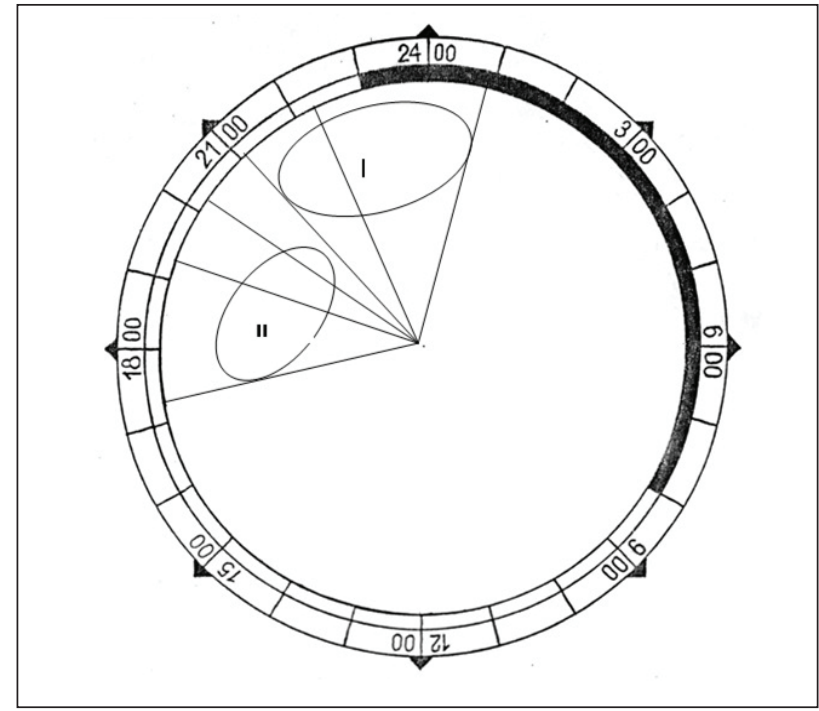

Figure 1. Cosinor of Circadian rhythm SABP prior to (I) and after (II) treatment at 07.00 a.m. by Altiazem PP-180 Amplitude prior to treatment - 16.99 2.52 (12.64-21.34); After - 10.52 \pm 1.66 (17.17-20.45)

Acrophase prior to treatment - 22.03 (20.07-24.59); After - 19.23 (17.17-20.45)

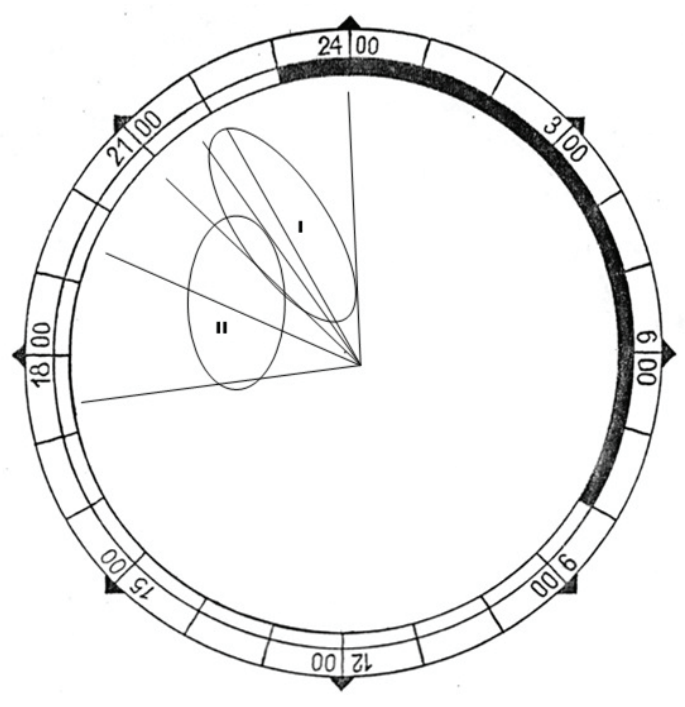

Figure 2. Cosinor of circadian rhythm DABT prior to (I) and after (II) treatment at 07.00 a.m. by Altiazem PP-180 Amplitude prior to treatment - 7.45 \pm 2.16 (3.72-11.18); After - 5.19 $\pm 1,60$ (2.42-7.96)

Acrophase prior to treatment - 22.01 (21.00-23.57);

After treatment - $19.50(17.38-21.48)$

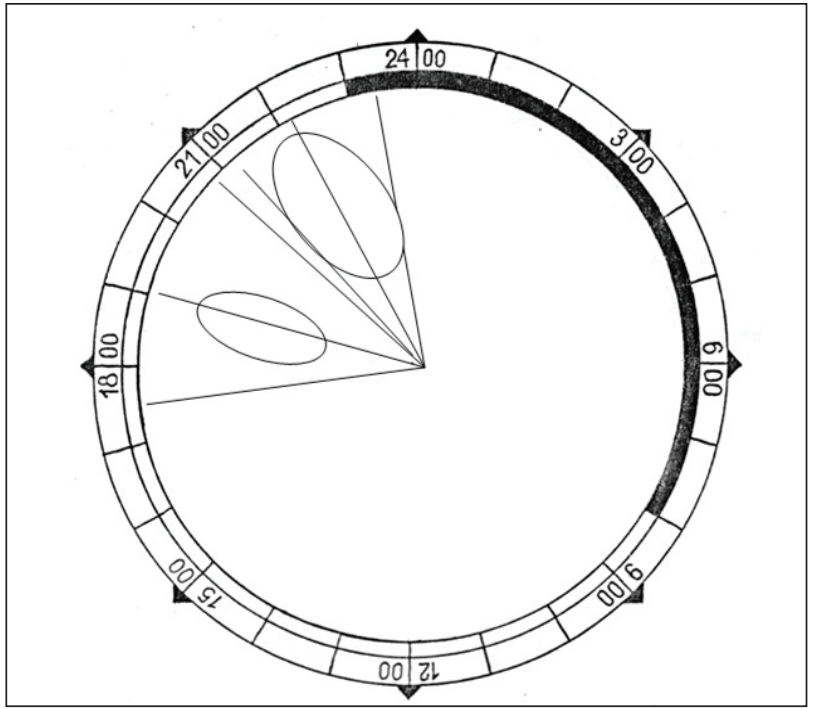

Figure 3. Cosinor of the circadian rhythm of average ABP prior to (I) and after treatment (II) by Altiazem PP-180 at 07.00 a.m.

Amplitude prior to treatment $-10.63 \pm 2.01$ (7.16-14.10);

After treatment $-6.93 \pm 1.42$ (4.48-9.39)

Acrophase prior to treatment 22.02 - (21.15-23.15);

After treatment - 19.01 (17.37-20.53)

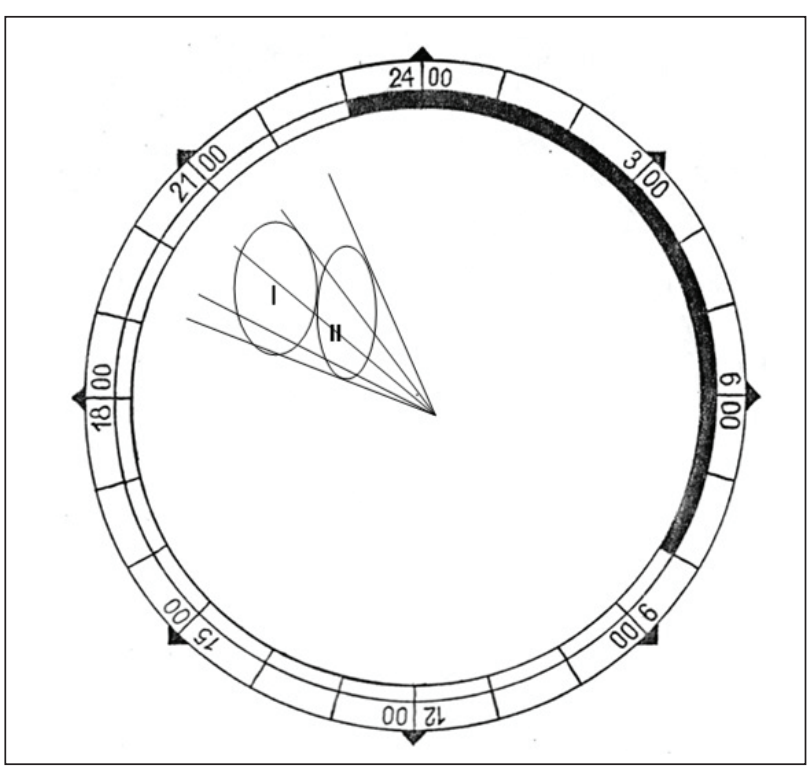

Figure 4. Cosinor of the circadian rhythm of SABP prior to (I) and after (II) treatment at 01.00 p.m. by Altiazem PP-180

Amplitude prior to treatment - 13.56 $\pm 1.67(10.67-16.46)$;

After - 13.49 $\pm 2.14(9.79-17.18)$

Acrophase prior to treatment - 21.20 (19.52-22.16);

After - 20.41 (19.39-21.34) 


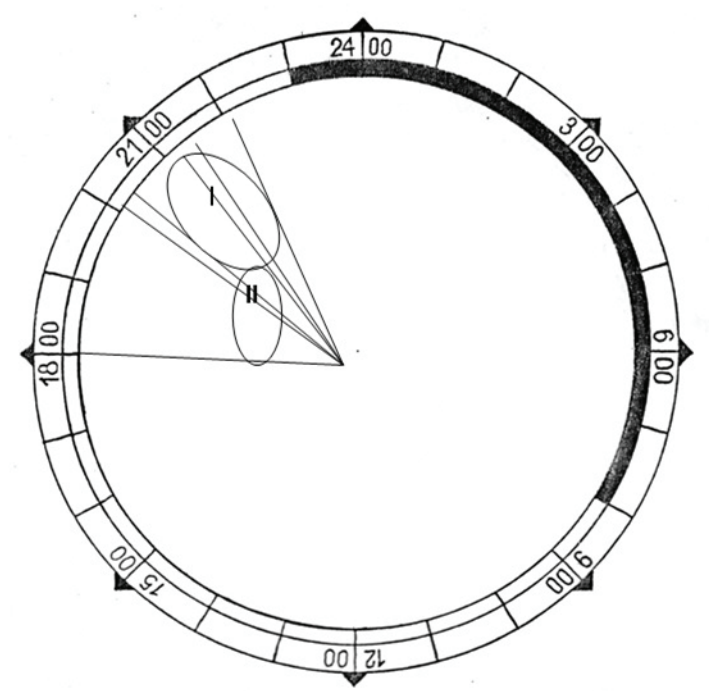

Figure 5. Cosinor of the circadian rhythm of average ABP prior to (I) and after (II) treatment at 01.00 p.m. by Altiazem PP-180

Amplitude prior to treatment $-10.45 \pm 1.13$ (8.50-12.40); After - 6.40土1.53(3.76-9.04)

Acrophase prior to treatment - 21.30 (20.28-22.06); After - 20.25 (18.21-21.40)

\section{$\underline{\text { Conclusion }}$}

1. Altiazem PP-180 causes a clear hypotensive effect in II degree $\mathrm{AH}$ patients when administered at different intake times both fixed and random under outpatient conditions.

2. The most evident hemodynamic effect of the hypotensive action of Altiazem PP-180 can be observed when administered at 07.00 a.m.; 10.00 a.m. and 10.00 p.m. with a normal work-rest routine.

3. When administered at 07.00 a.m., 10.00 a.m., and 10.00 p.m. Altiazem PP-180 causes a significant decrease in peripheral vascular resistance, end-systolic and end-diastolic volumes and an increase in cardiac output.

4. Hypotensive action of Altiazem PP-180 when administered at 01.00 p.m.; 04.00 p.m., and 07.00 p.m. as well as at random hours of the day showed a less effective hemodynamic effect: a decrease in cardiac output accompanied by an increase in total peripheral resistance and peripheral vascular resistance index.

It is considered worthwhile to continue the research of time-dependent effects of Altiazem PP-180 and blood circulation parameters in II degree arterial hypertension and concomitant coronary heart disease patients. 


\section{References:}

1. Baryshnikova G, Stepanova I, Chuprova N, Chorbinskaya S. The Role of Dihydropyridine Calcium Channel Blockers in Arterial Hypertension Treatment, Diagnostics and Treatment of Arterial Hypertension, Clinical Recommendations MH RF, Academic Medical Center AD of the President of RF: 2013.

2. Nedogoda S, Chumachek E, Lediayeva A, Tsoma V, SalasyukA. Comparative Efficacy of Fixed Combinations of Lizinopril with Amlodipin and Enalaprilum with Hydrochlorothiazide. Cardiovasccular Therapy and Prevention. 2013; 12 (2), pp. 25-29.

3. Ostroumova D, Smolyarchuk E, Kopchenov I. Dihydropyridine Calcium Channel Blockers in Arterial Hypertension Treatment: Efficacy and Safety of Felodipin. Consilium Medicum, 2016 (5), pp.23-29.

4. Recommendations on Diagnostics and Treatment of Arterial Hypertension ESH and ESC. Eurasian Cardiologic Journal, 2014 ;1, pp.80.

5. Yershova A, Meshkov A, Yakushin S, Lukyanov M, Moseychuk K, Martsevich S. Diagnostics and Treatment of Patients with Severe Hypercholesterolemia in Real Clinical Outpatient Practice (according to REKVAZA). Rational Pharmacotherapy in Cardiology, 2014; 10, pp. 612-616.

6. European Recommendations on Arterial Hypertension Therapy 2013. J. Hypertens., 2013 31(7), pp. 12811357.

7. Kislyak O. Arterial Hypertension Treatment of Patients with High Cardiovascular Risk in Light of Modern Recommendations and Observation Study Results. Cardiology, 2015 (5), pp.95-99.

8. Blisiots I, Destourius A, Stergiou G. Home vs. Ambulatory and Damage Pressure in Predicting Target Organ Damage in Hypertension: a Systematic Review and Meta-analysis. J. Hypertens., 2012 (30), pp. 12891299.

9. Morozova T. (Eds.) Pharmacotherapy of Chronic Cardio-Vascular Disease. Moscow, 2011.

10. Chazova I, Oshepkova I, Zhernakova Y. Diagnostics and Treatment of Arterial Hypertension. Clinical recommendations. Cardiology, 2015 (1), pp. 3-30.

11. The Task Force for the management of arterial hypertension of the European Society of Hypertension (ESH) and of the European Society of Cardiology (ESC). Eur. Heart J., 2013 (34), pp. 2159-2219.

12. Kodasbayev Sh, Zhangelova R, Almukhambetova Z. A Place of a New III Generation Calcium Channel Blocker and Arterial Hypertension Diagnostics and Treatment
Management. KazNMU Journal, 2016 (2), pp.16-17.

13. Myasoyedova S. Diltiazem: Its Place in Modern Therapy of Cardiovascular Disease. Atmosphere. Cardiology News, 2014 (3), pp. 11-15.

14. Chazova I, Zhernakova Y, Oshepkova I, Shalnova S, Yarovaya E, Konrady A, Boitsov S. Occurrence of Risk Factors of Cardio-Vascular Disease in Russian AH Patient Population. Cardiology, 2014 (10), pp. 4-12.

15. Chumakova O, Tipteva T, Reznichenko N, Zateishikov D. Association of Arterial Hypertension Complicated by Myocardial Hypertrophy and Cardiac Insufficiency with Lower Levels of Vascular Endothelial Growth Factor (VEGF-A165) in Blood Serum. Cardiology, 2015 (10), pp. 14-18

16. Bronsert M, Henderson W, Valuck R, et al. Comparative Effectiveness of Antihypertensive Therapeutic Classes and Treatment Strategies in the Initiation of Therapy in Primary Care Patients: a Distributed Ambulatory Research in Therapeutics Network (DARTNet) study. $J$ Am Board Fam Med, 2013 (26), pp. 529-538.

17. Sirivanasandha B, Sakaew A, Sutthivaiyakit K, et al. An Equivalence Trial Comparing Labetalol and Diltiazem in Controlling Emergence Hypertension after Supratentorial Tumor Surgery. Journal of the Medical Association of Thailand, 201598 (11), pp. 1104-1111.

18. Glezer M, Deyev A. How to Increase the Efficacy of Antihypertensive Therapy in Real Clinical Practice: The Results of a Russian Observation Program Forsage. Cardiology, 2016 (1), pp.18-24

19. Pravkina E, Nikulina N, Lukianov M, et al. Quality of Arterial Hypertension Patients Examination in Clinical Outpatient Departments, Clin. Med., 201593 (9), pp. 36-42.

20. Radchenko A. Some Aspects of Administration of Dihydropyridine Calcium Channel Blockers in Arterial Hypertension Treatment. Arterial Hypertension, 2013 (5), pp.31.

21. ECVD-RF Scientific and Organizational Committee. Project Epidemiology of Cardiovascular Disease in Different Regions of Russia (ECVD-RF). Study Design and Rationale. Prev. Med., 2013 (6), pp. 25-34.

22. Smolensky M, Hermida R, Reinberg A, SackettLundeen L, Portaluppi F. Circadian Disruption: New Clinical Perspective of Disease Pathology and Basis for Chronotherapeutic Intervention. Chronobiol Int, 2016 (16), pp. 1-19.

23. Khalberg F. Chronobiology. Cybernetic Collected Works, 1972 (9), pp. 189-247. 